\title{
Coronary artery disease: medical therapy
}

Ker JA, MBChB, MMed(Int), MD

Faculty of Health Sciences, University of Pretoria

Correspondence to: Prof James Ker, e-mail: james.ker@up.ac.za

\section{Abstract}

This article reviews the impact of medical therapy on the risk of atherosclerotic coronary artery disease.

SA Fam Pract 2010;52(4):305-306

\section{Background}

It is estimated that at the age of 40 years, the life-time risk to develop coronary artery disease is one in two for men and one in three for women. ${ }^{1}$ Atherosclerotic coronary artery disease begins in childhood and the risk factors influence the development of atherosclerosis throughout one's lifetime. ${ }^{2}$

A standardised case-control study of acute myocardial infarction in 52 countries, representing every inhabited continent, demonstrated that nine cardiovascular risk factors in all the countries are responsible for $90 \%$ of the population attributable risk in men and $94 \%$ in women: dyslipidaemia, hypertension, smoking, diabetes, abdominal obesity, diet poor in daily consumption of fruit and vegetables, lack of regular physical activity, lack of daily alcohol intake and psychological factors (mainly depression). ${ }^{3}$

An elevated cholesterol is the driving force of atherogenesis. Evidence indicates that a life-time low LDL-cholesterol level lowers the risk of atherosclerotic coronary artery disease by up to $80 \%$ compared with the general population. Intensive LDL-lowering therapy reduces the risk of atherosclerotic heart disease by $40 \%$ to $50 \%{ }^{4}$

\section{What is happening globally?}

In industrialised countries the rates of heart-disease related deaths are reducing due to lipid lowering therapy, hypertension treatment and a reduction in smoking. The largest contribution came from secondary preventive treatments for patients after myocardial infarction and revascularisation. Each death avoided by treating a patient with recognised coronary heart disease can yield an additional 7.5 years of life. Risk factor reduction has been shown to account for up to $79 \%$ of the total lifeyears gained in certain populations. The question to ask? Would it not be much more beneficial to start much earlier in a person's life to reduce the impact of cardiovascular risk factors by early recognition and treatment. New trends are emerging: increase in prevalence of hypertension, obesity and diabetes mellitus ${ }^{5}$ in contrast to developing countries in which the prevalence of atherosclerotic-related heart disease is increasing.

\section{What works in therapy?}

Cessation of smoking is associated with a relative risk reduction in mortality of up to $36 \% .{ }^{6}$ The benefits of smoking cessation are greater and accrue more rapidly in comparison to other important cardiovascular interventions. Patients who survived a myocardial infarction and then quit smoking reduce their mortality risk by $37 \%[95 \% \mathrm{Cl} 18$ to $52 \%]$ as compared to persistent smokers. Observational studies persistently reported a decreased number of coronary heart disease events in people who perform regular aerobic activity. Even one hour of walking per week is associated with a lower risk.

Reducing LDL-cholesterol by about $1.5 \mathrm{mmol} / \mathrm{L}$ reduces by about a third the incidence of ischaemic heart disease and ischaemic stroke independently of age or blood pressure. ${ }^{7}$

Reducing dietary salt by $3 \mathrm{~g}$ per day can reduce blood pressure, new cases of coronary heart disease, stroke and deaths to a similar level as the effect of other risk factor reduction. ${ }^{8}$

Aspirin used for primary prevention can reduce the relative risk of a non-fatal myocardial infarction by $23 \%$, but has no effect on mortality. In secondary prevention aspirin reduces 
the risk of non-fatal myocardial infarction by about $31 \%$ and the relative risk of death by $9 \% .^{9}$

Niacin can reduce major coronary events by $\pm 25 \%$ (95\% Cl 13 to $35 \%)$ according to a meta-analysis. ${ }^{10}$ In patients with stable ischaemic (coronary) heart disease and a normal left ventricular ejection fraction, a meta-analysis showed that ACE-inhibitors reduced relative risk of mortality by $13 \%(95 \% \mathrm{Cl} 6$ to $19 \%)$ and non-fatal myocardial infarction by $17 \%(95 \% \mathrm{Cl} 6$ to $27 \%) .{ }^{11}$ In the same metaanalysis angiotensin receptor blockers reduce a composite of cardiovascular mortality, non-fatal myocardial infarction and stroke by $12 \%$ (95\% Cl 0 to $25 \%$ ). Beta-blockers, used as a secondary prevention measure, can reduce mortality and reinfarction by up to $23 \%(95 \% \mathrm{Cl} 16$ to $30 \%) .{ }^{12}$

The use of $\mathrm{N}-3$ polyunsaturated fatty acids after a myocardial infarction results in a $45 \%$ reduction in sudden death and a $30 \%$ reduction in cardiovascular death. ${ }^{13}$

\section{How effective is optimal medical therapy?}

In a large trial, the use of five drugs [aspirin, clopidogrel, beta-blocker, statin renin-angiotensin system blocker (ACE-I/ARB)] was tested versus the use of one of these drugs or none in survivors of a first acute myocardial infarct. The use of the five drugs reduced relative risk of mortality at one year by $74 \%(95 \% \mathrm{Cl} 62 \text { to } 82 \%)^{13}$ versus one or alone of the drugs used. ${ }^{14}$

In the chronic artery disease setting, non-adherence to cardio protective medications (beta-blockers, statins, ACEinhibitors) was associated with a $10-40 \%$ relative increase in risk of cardiac hospitalisations and a $50-80 \%$ relative increase in mortality. ${ }^{15}$

\section{What does not work? ${ }^{16}$}

Dietary supplements, herbal preparations and alternative therapies are popular with patients, but they are of dubious benefit. The data for most such interventions are inconclusive.

Vitamin E supplements and antioxidant therapy for primary and secondary prevention of atherosclerotic cardiovascular events had no effect and even suggested increased mortality with use of

Vitamin E. Garlic, when tested versus placebo, had no effect on LDL-cholesterol levels.

Reducing homocysteine levels by using folic acid and B-vitamins has not shown any benefit in many randomised trials.

\section{References}

1 Lloyd-Jones DM, Larson MG, et al. Life-time risk of developing coronary artery disease. Lancet 1999;353:89-92.

2 Berenson GS, Pickoff AS. Preventive cardiology and its potential influence on the early natural history of adult heart disease: the Bogulusa Heart Study and the Heart SMART Program. Am J Med Sci 1995;310 [Suppl 1]: S135-S128.

3 Yusuf S, Hawken S, et al. Effect of potentially modifiable risk factor associated with myocardial infarction in 52 countries (the INTERHEART study): case-control study. Lancet 2004;364:937-952.

4 Grundy SM. Is lowering low-density lipoprotein (LDL) an effective strategy to reduce cardiac risk? Circulation 2008;117:569-573.

5 Brown JR, O'Connon GT. Coronary heart disease and prevention in the United States. N Engl J Med 2010;362:2150-2153.

6 Critchley JA, Capewell S. Mortality risk reduction associated with smoking cessation in patients with coronary heart disease: a systematic review. JAMA 2003;290:86-97.

7 Cholesterol Treatment Triallist (CTT) Collaboration. Efficacy and safety of cholesterol-lowering treatment: prospective metaanalysis of data from 90056 participations in 14 randomised trials of statins. Lancet 2005;366:1267-1278.

8 Bibbens-Domingo K, Chertow GM, et al. Projected effect of dietary salt reductions on fatal cardiovascular disease. $N$ Engl $J$ Med 2010;10.1056/NEJM oa 0907355.

9 Baigent C, Blackwell L, et al. Aspirin in the primary and secondary prevention of vascular disease: collaborative meta-analysis of individual participant data from randomised trials. Lancet 2009;373:1849-1860

10 Bruckert E, Labreuche J, Amarenco P. Meta-analysis of the effect of nicotinic acid alone or in combination on cardiovascular events and atherosclerosis. Atherosclerosis 2010;210:353-361.

11 Baker WL, Coleman Cl, et al. Systematic review: comparative effectiveness of angiotensin converting enzyme inhibitors or Angiotension-11-Receptor blockers for ischaemic heart disease. Ann Intern Med 2009;151:861-871.

12 Data from Chae CJ, Hennekens $\mathrm{CH}$. Beta blockers: in Hennekens $\mathrm{CH}$ (ed) clinical trials in cardiovascular disease: a companion to Braunwald's Heart Disease. Philadelphia WB Saunders 1999;p84.

13 Khavandi A, Khavandi K, et al. N-3 polyunsaturated fatty acids are still underappreciated and underused post myocardial infarction. Heart 2009;85:540-541.

14 Bramlage P, Messer C, et al. The effect of optimal medical therapy on 1-year mortality after acute myocardial infarction. Heart 2010;96:604-609.

15 Ho PM, Magid DJ, et al. Medication non-adherence is associated with a broad range of adverse outcomes in patients with coronary artery disease. Am Heart J 2008;155:772-779.

16 Lewis SJ. Prevention and treatment of atherosclerosis: a Practitioner's guide for 2008. Am J Med 2009;122:S38-S50. 